\title{
Cadherin 5 Is a Significant Risk Factor for Hematogenous Recurrence and a Prognostic Factor in Locally Advanced Gastric Cancer
}

\author{
MIKITO INOKUCHI ${ }^{1}$, KYOKO HIGUCHI $^{1}$, YOKO TAKAGI $^{2}$, TOSHIRO TANIOKA $^{1}$, \\ MASATOSHI NAKAGAWA ${ }^{1}$, KENTARO GOKITA ${ }^{1}$, KEISUKE OKUNO ${ }^{1}$ and KAZUYUKI KOJIMA ${ }^{3}$ \\ ${ }^{1}$ Department of Gastrointestinal Surgery, ${ }^{2}$ Department of Surgical Specialties, \\ ${ }^{3}$ Department of Minimally Invasive Surgery, Tokyo Medical and Dental University, Tokyo, Japan
}

\begin{abstract}
Background/Aim: Cadherin 5 (CDH5) is important for adhesion in epithelial cells, and expressed in tumor cells in several malignancies. In the present study, we evaluated the clinical significance of $\mathrm{CDH} 5$ protein expression in locally advanced gastric cancer. Materials and Methods: Tumor tissues obtained from 113 patients with advanced gastric adenocarcinoma who underwent gastrectomy were analyzed. Results: High CDH5 expression was significantly associated with recurrence $(p=0.017)$, especially hematological recurrence $(p=0.022)$. High $C D H 5$ expression was a significant risk factor for hematogenous recurrence on multivariate analysis (odds ratio $[O R]=3.9$, confidential interval [CI] 1.0-15, $p=0.043$ ). Patients with high CDH5 expression had a significantly shorter progression-free interval (RFI, $p=0.010)$ than patients with low CDH5 expression. High CDH5 expression was an independent prognostic factor on multivariate analysis of RFI (hazard ratio[HR]=2.2, 95\% CI 1.1-4.3, $p=0.021$ ). Conclusion: CDH5 may play a key role in hematogenous recurrence of advanced gastric cancer and may be a viable treatment target.
\end{abstract}

Gastric cancer (GC) continues to have a high incidence worldwide and is one of the common causes of cancerrelated death (1). Surgery followed by adjuvant chemotherapy is standard treatment for advanced GC, although chemotherapy is a standard treatment for recurrent or distant metastatic disease. Only two molecular-targeting

Correspondence to: Mikito Inokuchi, Department of Gastric Surgery, Tokyo Medical and Dental University, 1-5-45, Yushima, Bunkyo-ku, Tokyo 113-8519, Japan. Tel: +81 358035261, Fax: +81 358030139, e-mail: m-inokuchi.srg2@tmd.ac.jp

Key Words: Cadherin 5, advanced gastric cancer, hematogenous recurrence. drugs, antibodies against HER2 or VEGFR2, are clinically available for the treatment of GC. Many candidate prognostic factors or promising biomarkers have been reported, although few molecular targets are clinically valuable.

The superfamily of transmembrane cadherin (CDH) proteins encompasses more than 100 members in humans, and types I and II CDHs are generally considered to play key roles in the progression of various malignant tumors (2). For example, the epithelial cell-cell adhesion molecule cadherin 1 (CDH1), also known as epithelial cadherin, plays an important role in the suppression of tumor progression. Down-regulation or inactivation of $\mathrm{CDHI}$ is caused by mutation or hypermethylation in diffuse-type GC according to Lauren's pathological classification, and loss of $\mathrm{CDH} 1$ is a well-known epigenetic change in hereditary GC (3-5). Cadherin 5 (CDH5), also known as vascular endothelial $\mathrm{CDH}$, is one type II CDH. CDH5 plays an important role in cell-cell adhesion, contact inhibition of growth, and inhibition of migration and apoptosis of endothelial cells (6). However, aberrant CDH5 expression is observed in tumor cells of various malignancies. CDH5 has a crucial role in the process of vasculogenic mimicry of glioma or melanoma cells $(7,8)$. CDH5 promotes tumor cell proliferation and invasion by stimulating transforming growth factor (TGF) $-\beta$ signaling in breast cancer cells (9-11).

We previously reported the relation of the immunohistochemical expression of CDH5 to tumor progression and poor survival in differentiated-type gastric cancer classified according to the World Health Organization (WHO) pathological categories (12). Metastatic sites of GC often differ among pathological categories, i.e., differentiated and undifferentiated types, or intestinal and diffuse types. Undifferentiated-type or diffuse-type GC has higher incidences of peritoneal dissemination and poorer survival than differentiated-type or intestinal-type GC (13-16). The present study was designed to evaluate the relation of CDH5 
expression to the recurrence pattern after curative gastrectomy and the survival of patients with locally advanced GC, including both differentiated-type and undifferentiated-type tumors.

\section{Patients and Methods}

Patients. The study group comprised 113 patients who had a pathological diagnosis of advanced gastric adenocarcinoma and underwent gastrectomy without residual tumor from January 2004 through December 2008 in the Department of Gastrointestinal Surgery, Tokyo Medical and Dental University, Japan. No patient received adjuvant therapy. Each tumor was classified according to the TNM classification (17). All tumors were pathologically classified into differentiated type (papillary or tubular adenocarcinoma) and undifferentiated type (poorly differentiated adenocarcinoma, signet-ring cell carcinoma, or mucinous adenocarcinoma) in accordance with the WHO pathological classification. All patients were provided a sufficient explanation of the study, and written informed consent was obtained. This study was approved by the Institutional Review Board of Tokyo Medical and Dental University (No. 831). All patients were evaluated for recurrent disease by diagnostic imaging (computed tomography, ultrasonography, magnetic resonance imaging, or endoscopy) every 3 to 6 months. Positron emission tomography and bone scintigraphy were additionally performed, if necessary. The median follow-up was 60 months (range=3-109 months). Twenty-two patients $(19 \%)$ received postoperative adjuvant chemotherapy with $\mathrm{S}-1$ (an oral fluoropyrimidine preparation consisting of tegafur, gimeracil, and oteracil potassium; Taiho Co., Tokyo, Japan) alone. A total of 47 (42\%) patients had recurrent disease. Recurrence patterns were classified into four groups: hematogenous (liver, lung, bone, bone marrow, and brain), lymphatic, peritoneal, and local recurrence. Finally, 45 patients (40\%) deceased of recurrent disease, and $3(3 \%)$ deceased of other causes.

Immunohistochemistry. The detailed method used to perform immunohistochemical analysis was described in our previous report (12). Representative formalin-fixed, paraffin-embedded tissue blocks were sliced into 4- $\mu$ m-thick sections. After deparaffinization and rehydration, antigen retrieval was performed. Subsequently, endogenous peroxidase and non-specific binding were blocked. The slides were incubated with a polyclonal rabbit antibody against CDH5 (dilution, 1:100) at $4^{\circ} \mathrm{C}$ overnight. The primary antibody (ab71285 ${ }^{\circledR}$ ) was purchased from Abcam (Cambridge, UK). The sections were incubated with peroxidase-labeled antirabbit or antimouse antibodies (Histofine Simple Stain MAX PO; Nichirei Biosciences Inc., Tokyo, Japan) for $30 \mathrm{~min}$ at room temperature. Peroxidase activity was detected with diaminobenzidine (DAB; Nichirei Biosciences). Subsequently, the sections were counterstained with Mayer's hematoxylin (Wako, Tokyo, Japan). Negative controls were treated similarly, except that the antibodies were replaced by normal rabbit IgG (Santa Cruz Biotechnology, Inc., Santa Cruz, CA, USA). Strongly stained gastric specimens obtained from the same block were set as positive controls to reduce bias from the staining conditions during each session of immunohistochemical analysis.

Interpretation of immunohistochemical staining. The stained slides were evaluated by two separate investigators (KH and YT) who were blinded to the patients' outcomes. The investigators counted whole stained cancer cells of representative cross-sectional slices. To evaluate discretely distributed cancer cells, we counted at least three fields per section of the invasive front of each tumor. The system used to score CDH5 staining was modified in this study because not only membranous expression, but also cytoplasmic expression was often observed in undifferentiated-type gastric cancer. The staining intensity was scored into three grades as follows: 0 , no staining; 1 , weakly positive; and 2, moderately or strongly positive. The staining extent (positive frequency) was also scored into three grades according to the percentage of stained tumor cells as follows: $0,<10 \% ; 1,10 \%$ to $50 \%$; and $2,>50 \%$ stained cells. For statistical analysis, composite scores were calculated by adding the intensity and extent scores. Composite scores of $\geq 3$ were defined as high expression, and scores of $<3$ were defined as low expression.

Statistical analysis. Categorical data were compared with the use of the chi-square test or Fisher's exact test, as appropriate. Risk factors for hematogenous recurrence were evaluated by binary logistic multiple regression analysis using dummy variables with values of $p<0.1$. Kaplan-Meier curves were plotted to assess the effect of $\mathrm{CDH} 5$ expression on the relapse-free interval (RFI), and different survival curves were compared using the log-rank test. Before multivariable analysis it was confirmed that prognostic factors did not strongly correlate with each other. Multivariable Cox proportional-hazards regression models were used to assess the prognostic significance of $\mathrm{CDH} 5$ expression and of several clinicopathological factors associated with RFI. $p$-Values of $<0.05$ were considered to indicate statistical significance. All statistical analyses were performed with the statistical software package SPSS 24 (SPSS Japan Inc., Tokyo, Japan).

\section{Results}

CDH5 expression was observed in both the cytoplasm and the membrane of cancer cells (Figure 1). High CDH5 expression was observed in 62 (55\%) tumors (Figure 1A and B). CDH5 expression was also present in vascular endothelial cells within cancerous and non-cancerous tissue, but was not present in non-cancerous epithelial cells. In addition, high CDH5 expression was also observed in liver metastases obtained by surgical resection from 2 enrolled patients (Figure 1C and D). The relationship between CDH5 expression and clinicopathological factors are shown in Table I. High CDH5 expression was significantly associated with male sex $(p=0.002)$, higher age $(>65$ years, $p=0.013)$, and differentiated type $(p=0.001)$, but not with serosal invasion, venous invasion, lymphatic invasion, extent of lymph-node metastases, or tumor stage (Stage I/II vs. III). CDH5 expression was significantly associated with recurrence $(p=0.017)$, especially hematological recurrence $(p=0.022)$, but was not significantly associated with peritoneal or distant lymphatic recurrence. High CDH5 expression was a significant risk factor for hematogenous recurrence on multivariable analysis (odds ratio $=3.9$, confidential interval [CI] 1.0-15, $p=0.043$; Table II), whereas serosal invasion was 

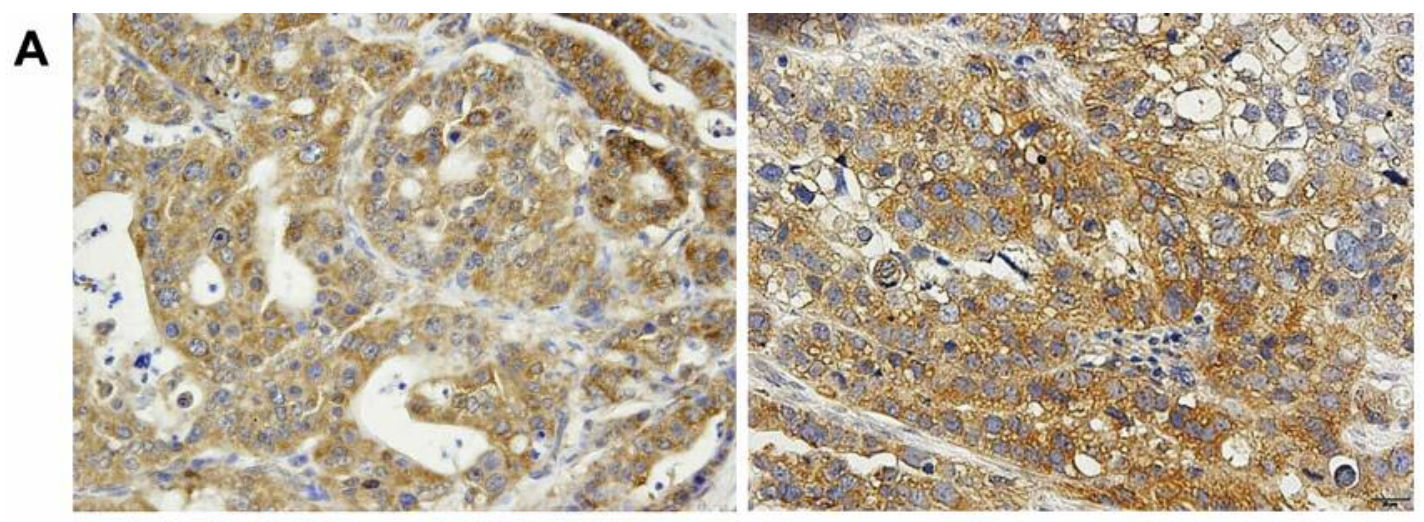

B
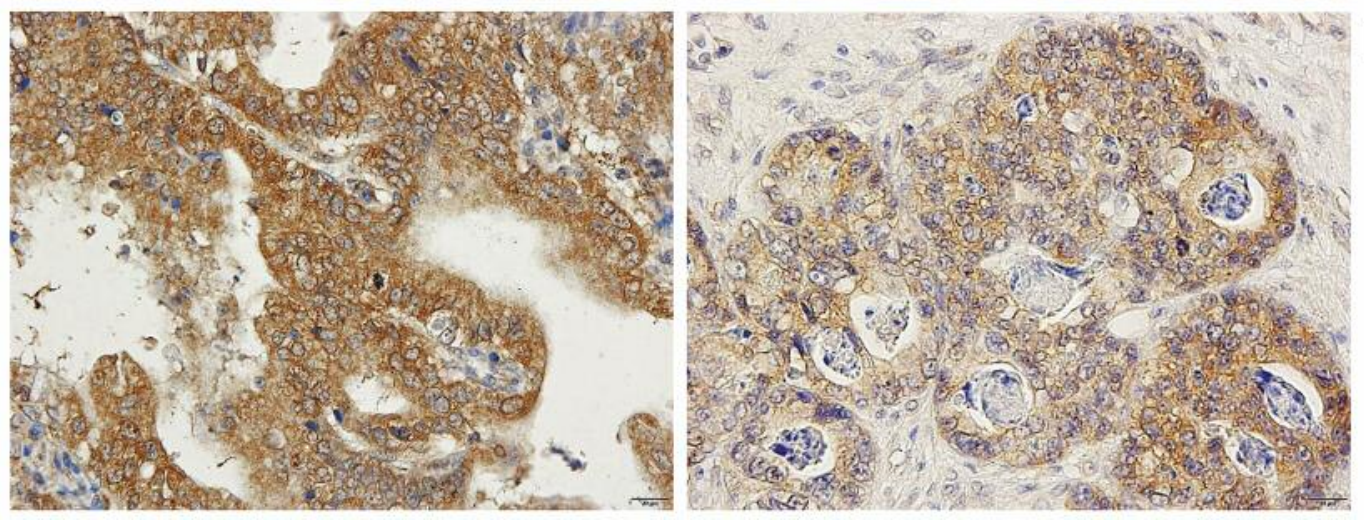

Figure 1. Immunostaining for CDH5. Representative primary gastric cancers, differentiated type (A), undifferentiated type (B), and liver metastasis $(C, D)$. Magnification $\times 400$.
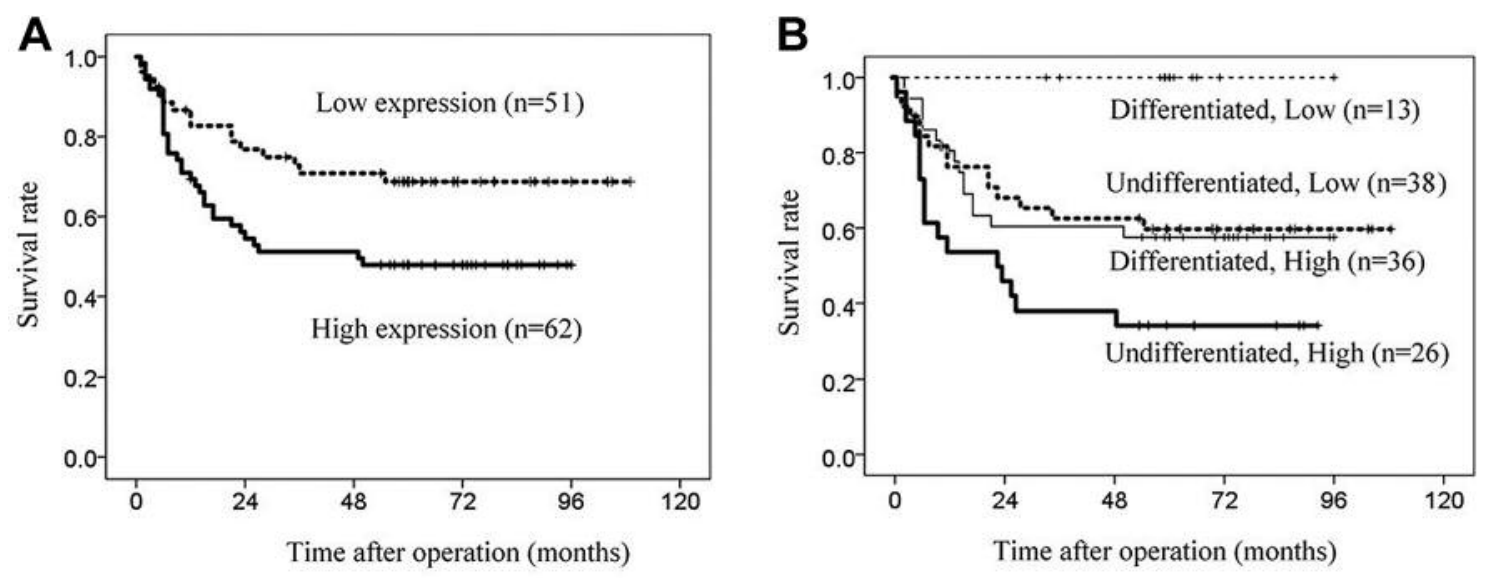

Figure 2. Survival of all patients. The Kaplan-Meier curve for the relapse-free interval (RFI, A) of patients with CDH5 expression and the RFI (B) of patients with CDH5 expression and different pathological types (differentiated or undifferentiated type).

slightly $(p=0.067)$, but not significantly associated with hematogenous recurrence on multivariable analysis $(p=0.12)$. Among patients with hematogenous recurrence, high $\mathrm{CDH} 5$ expression was found in 8 of 10 patients with liver metastasis, 3 of 3 patients with lung metastasis, 2 of 3 patients with bone metastasis, and 1 of 1 patient with bone marrow metastasis.
Patients with high CDH5 expression had a significantly shorter RFI ( $p=0.010$, Figure 2A) than patients with low CDH5 expression. In both differentiated and undifferentiated GC, CDH5 was significantly associated with a poor RFI ( $p=0.008$ and 0.024 , Figure 2B). No recurrent tumor was found in patients who had differentiated-type GC with low CDH5 expression. 
Table I. Correlations of the expressions of $\mathrm{CDH} 5$ with clinicopathological factors.

\begin{tabular}{|c|c|c|c|c|c|c|c|}
\hline \multirow[t]{3}{*}{ Clinicopathological factors } & & \multirow{3}{*}{$\mathrm{n}$} & \multicolumn{4}{|c|}{ CDH5 expression } & \multirow[t]{3}{*}{$p$-Value } \\
\hline & & & \multicolumn{2}{|c|}{ High $(n=62)$} & \multicolumn{2}{|c|}{ Low $(n=51)$} & \\
\hline & & & $\mathrm{n}$ & $(\%)$ & $\mathrm{n}$ & $(\%)$ & \\
\hline \multirow[t]{2}{*}{ Age (years) } & $>65$ & 61 & 40 & $(66)$ & 21 & (34) & 0.013 \\
\hline & $<65$ & 52 & 22 & $(41)$ & 30 & (59) & \\
\hline \multirow[t]{2}{*}{ Gender } & Female & 25 & 7 & (28) & 18 & (72) & 0.002 \\
\hline & Male & 88 & 55 & $(62)$ & 33 & $(38)$ & \\
\hline \multirow[t]{2}{*}{ Main tumor location } & Upper & 31 & 20 & $(65)$ & 11 & (35) & 0.21 \\
\hline & Middle or Lower & 82 & 42 & (51) & 40 & (49) & \\
\hline \multirow{2}{*}{ Pathological classification } & Undifferentiated & 64 & 26 & $(41)$ & 38 & (59) & 0.001 \\
\hline & Differentiated & 49 & 36 & (73) & 13 & (27) & \\
\hline \multirow[t]{2}{*}{ Serosal invasion } & Positive & 47 & 29 & $(62)$ & 18 & (38) & 0.22 \\
\hline & Negative & 66 & 33 & $(50)$ & 33 & $(50)$ & \\
\hline \multirow[t]{2}{*}{ Venous invasion } & Positive & 95 & 54 & (57) & 41 & (43) & 0.33 \\
\hline & Negative & 18 & 8 & (44) & 10 & (56) & \\
\hline \multirow[t]{2}{*}{ Lymphatic invasion } & Positive & 93 & 53 & $(57)$ & 40 & (43) & 0.33 \\
\hline & Negative & 20 & 9 & $(45)$ & 11 & (55) & \\
\hline \multirow[t]{2}{*}{ Lymph-node metastasis } & Positive & 73 & 42 & (58) & 31 & $(42)$ & 0.44 \\
\hline & Negative & 40 & 20 & $(50)$ & 20 & $(50)$ & \\
\hline \multirow[t]{2}{*}{ Tumor stage } & III & 59 & 34 & $(58)$ & 25 & $(42)$ & 0.54 \\
\hline & IB/II & 54 & 28 & $(52)$ & 26 & (48) & \\
\hline \multirow[t]{2}{*}{ Recurrence } & Positive & 47 & 32 & $(68)$ & 15 & (32) & 0.017 \\
\hline & Negative & 66 & 30 & $(45)$ & 36 & (55) & \\
\hline \multirow[t]{2}{*}{ Peritoneal recurrence } & Positive & 25 & 15 & $(60)$ & 10 & (40) & 0.56 \\
\hline & Negative & 88 & 47 & (53) & 41 & (47) & \\
\hline \multirow[t]{2}{*}{ Hematogenous recurrence } & Positive & 16 & 13 & $(81)$ & 3 & (19) & 0.022 \\
\hline & Negative & 97 & 49 & $(51)$ & 48 & (49) & \\
\hline \multirow{2}{*}{ Distant lymph-node recurrence } & Positive & 23 & 15 & (68) & 8 & (32) & 0.26 \\
\hline & Negative & 90 & 47 & (52) & 43 & (48) & \\
\hline
\end{tabular}

High CDH5 expression was an independent prognostic factor for RFI on multivariate analysis of clinicopathological features affecting RFI adjusted for serosal invasion by primary tumor, lymphatic metastasis, and pathological type (Hazard ratio $[\mathrm{HR}]=2.2$, 95\%CI 1.1-4.3, $p=0.021$; Table III).

\section{Discussion}

Our results showed that high $\mathrm{CDH} 5$ protein expression was an independent risk factor for hematogenous recurrence in locally advanced GC. In addition, high CDH5 expression was an independent prognostic factor for RFI. CDH5 expression on immunohistochemical analysis was specifically evident in endothelial cells, although aberrant extra-vascular expression of CDH5 was observed in another study of GC (18) and several other malignancies $(11,19)$. Aberrant CDH5 expression is associated with the development of vasculogenic mimicry, which is a blood supply system independent of endothelial vessels in tumor cells from different origins. In melanoma cells, CDH5 protein or gene expression is strongly expressed in aggressive, but not nonaggressive tumor cells, and down-regulation of CDH5 gene expression inhibits vasculogenic mimicry (7). CDH5 regulates erythropoietin-producing hepatocellular receptor 2 as a key regulatory element in the process of vasculogenic mimicry in melanoma cells (20). Also in glioma cells, the level of CDH5 mRNA correlated significantly with more aggressive tumor behavior and poor patient survival, and knockdown of CDH5 inhibited vasculogenic mimicry, especially in the presence of hypoxia (8). Blocking CDH5 function by monoclonal antibodies was shown to inhibit tumor angiogenesis and growth in mouse models of glioma or epidermoid tumors $(21,22)$. In esophageal cancer tissues, CDH5 mRNA expression was significantly associated with mRNA expression of vascular endothelial growth factor-A, which promotes tumor angiogenesis (23). In addition, knockdown of CDH5 down-regulates Smad2 phosphorylation and transforming growth factor-beta target gene expression in a breast cancer cell line (11). CDH5 affects cell proliferation by enhancing the TGF-beta/Smad signaling pathway, which 
Table II. Risk factors for hematogenous recurrence.

\begin{tabular}{|c|c|c|c|c|c|c|}
\hline \multirow[t]{2}{*}{ Risk factors } & \multicolumn{2}{|c|}{ Univariate } & \multirow[b]{2}{*}{$p$-Value } & \multicolumn{3}{|c|}{ Multivariate } \\
\hline & Positive (n) & Negative (n) & & OR & $95 \% \mathrm{CI}$ & $p$-Value \\
\hline \multicolumn{7}{|l|}{ Age } \\
\hline$>65$ years & 7 & 54 & 0.38 & & & \\
\hline$<65$ years & 9 & 43 & & & & \\
\hline \multicolumn{7}{|l|}{ Gender } \\
\hline Male & 15 & 73 & 0.12 & & & \\
\hline Female & 1 & 24 & & & & \\
\hline \multicolumn{7}{|l|}{ Main tumor location } \\
\hline Upper & 6 & 25 & 0.37 & & & \\
\hline Middle/Lower & 10 & 72 & & & & \\
\hline \multicolumn{7}{|l|}{ Pathological type } \\
\hline Undifferentiated & 8 & 56 & 0.56 & & & \\
\hline Differentiated & 8 & 41 & & & & \\
\hline \multicolumn{7}{|l|}{ Serosal invasion } \\
\hline Positive & 10 & 37 & 0.067 & 2.4 & $0.8-7.5$ & 0.12 \\
\hline Negative & 6 & 60 & & 1 & & \\
\hline \multicolumn{7}{|l|}{ Venous invasion } \\
\hline Positive & 15 & 80 & 0.46 & & & \\
\hline Negative & 1 & 17 & & & & \\
\hline \multicolumn{7}{|l|}{ Lymphatic invasion } \\
\hline Positive & 13 & 80 & $>0.99$ & & & \\
\hline Negative & 3 & 17 & & & & \\
\hline \multicolumn{7}{|c|}{ Lymph-node metastasis } \\
\hline Positive & 13 & 60 & 0.13 & & & \\
\hline Negative & 3 & 37 & & & & \\
\hline \multicolumn{7}{|l|}{ CDH5 expression } \\
\hline High & 13 & 49 & 0.022 & 3.9 & $1.0-15$ & 0.043 \\
\hline Low & 3 & 48 & & 1 & & \\
\hline
\end{tabular}

OR: Odds ratio; CI: confidence interval.

can also promote tumor angiogenesis or epithelialmesenchymal transition (11). These findings suggest that CDH5 expression can contribute to hematogenous recurrence through vasculogenic mimicry and tumor angiogenesis.

The main site of hematogenous recurrence of GC is the liver, and hematogenous recurrence often occurs soon after gastrectomy (24). Poorly differentiated medullary-type and well-differentiated type tumors often cause hematogenous metastasis in GC (25). Moreover, vascular mimicry occurs especially in poorly differentiated type (26). In several studies, non-serosal invasive tumors, venous invasion, or lymphatic metastasis was associated with hematogenous recurrence in GC $(14,27)$, although these factors were not significantly associated with hematogenous recurrence in the present study. Alfa-fetoprotein-producing GC is often accompanied by liver metastasis (28), although only one tumor of that type was included in our study.

The present study was a single institutional retrospective study, and CDH5 gene expression was not investigated. In another study of $\mathrm{GC}$, overexpression of CDH5 mRNA as compared with non-cancerous tissue was detected in about half of all GCs. Advanced-stage tumors, or diffuse- or mixed-type tumors based on Laure's classification, had slightly elevated mRNA levels (18). CDH5 gene alteration was not shown in another study (5). Membranous CDH5 expression was assessed in our previous study, because CDH5 is a trans-membrane protein that promotes cell adhesion, similar to CDH1 (2). However, both membranous and cytoplasmic CDH5 expressions were found in the present studies. Cytoplasmic CDH5 expression was commonly observed in other studies $(11,18,19)$.

In conclusion, high CDH5 immunohistochemical expression was a significant risk factor for hematogenous recurrence and was a predictor of survival in locally advanced GC treated by surgery alone. Serum soluble CDH5 could be measured and was an independent prognostic factor in breast cancer (29); therefore, serum CDH5 should be evaluated in patients with $\mathrm{GC}$ in the future. The inhibition of CDH5 may serve as a target for the prevention of tumor angiogenesis and hematogenous metastasis in GC. 
Table III. Prognostic factors in univariate and multivariate Cox proportional hazards regression models for relapse-free interval.

\begin{tabular}{|c|c|c|c|c|c|}
\hline \multirow[t]{2}{*}{ Prognostic factors } & \multicolumn{2}{|c|}{ Univariate (log-rank) } & \multicolumn{3}{|c|}{ Multivariate } \\
\hline & 5-year RFI (\%) & $p$-Value & HR & $95 \% \mathrm{CI}$ & $p$-Value \\
\hline \multicolumn{6}{|l|}{ Age } \\
\hline$>65$ years & 60 & 0.90 & & & \\
\hline$<65$ years & 56 & & & & \\
\hline \multicolumn{6}{|l|}{ Gender } \\
\hline Male & 58 & 0.92 & & & \\
\hline Female & 60 & & & & \\
\hline \multicolumn{6}{|l|}{ Main tumor location } \\
\hline Upper & 47 & 0.16 & & & \\
\hline Middle/Lower & 63 & & & & \\
\hline \multicolumn{6}{|l|}{ Pathological type } \\
\hline Undifferentiated & 50 & 0.055 & 1.6 & $0.82-3.1$ & 0.17 \\
\hline Differentiated & 69 & & 1 & & \\
\hline \multicolumn{6}{|l|}{ Serosal invasion } \\
\hline Positive & 26 & $<0.001$ & 4.7 & $2.3-9.5$ & $<0.001$ \\
\hline Negative & 83 & & 1 & & \\
\hline \multicolumn{6}{|c|}{ Lymph-node metastasis } \\
\hline Positive & 42 & $<0.001$ & 3.2 & $1.2-8.6$ & 0.017 \\
\hline Negative & 87 & & 1 & & \\
\hline \multicolumn{6}{|l|}{ CDH5 expression } \\
\hline High & 48 & 0.010 & 2.2 & $1.1-4.3$ & 0.021 \\
\hline Low & 72 & & 1 & & \\
\hline
\end{tabular}

RFI: Relapse-free interval; HR: hazard ratio; CI: confidence interval.

\section{Conflicts of Interest}

The Authors have no conflicts of interest or financial ties to disclose.

\section{References}

1 Torre LA, Bray F, Siegel RL, Ferlay J, Lortet-Tieulent J and Jemal A: Global cancer statistics, 2012. CA Cancer J Clin 65: 87-108, 2015.

2 van Roy F: Beyond E-cadherin: roles of other cadherin superfamily members in cancer. Nat Rev Cancer 14: 121-134, 2014.

3 Becker KF, Atkinson MJ, Reich U, Becker I, Nekarda H, Siewert JR and Höfler H: E-cadherin gene mutations provide clues to diffuse type gastric carcinomas. Cancer Res 54: 3845-3852, 1994.

4 Machado JC, Oliveira C, Carvalho R, Soares P, Berx G, Caldas C, Seruca R, Carneiro F and Sobrinho-Simöes M: E-cadherin gene $(\mathrm{CDH} 1)$ promoter methylation as the second hit in sporadic diffuse gastric carcinoma. Oncogene 20: 1525-1528, 2001.

5 Cancer Genome Atlas Research Network: Comprehensive molecular characterization of gastric adenocarcinoma. Nature 513: 202-209, 2014.

6 Cavallaro U, Liebner S and Dejana E: Endothelial cadherins and tumor angiogenesis. Exp Cell Res 312: 659-667, 2006.
7 Hendrix MJ, Seftor EA, Meltzer PS, Gardner LM, Hess AR, Kirschmann DA, Schatteman GC and Seftor RE: Expression and functional significance of VE-cadherin in aggressive human melanoma cells: role in vasculogenic mimicry. Proc Natl Acad Sci USA 98: 8018-8023, 2001.

8 Mao XG, Xue XY, Wang L, Zhang X, Yan M, Tu YY, Lin W, Jiang XF, Ren HG, Zhang W and Song SJ: CDH5 is specifically activated in glioblastoma stemlike cells and contributes to vasculogenic mimicry induced by hypoxia. Neuro Oncol 15: 865-879, 2013.

9 Haidari M, Zhang W, Caivano A, Chen Z, Ganjehei L, Mortazavi A, Stroud C, Woodside DG, Willerson JT and Dixon RA: Integrin $\alpha 2 \beta 1$ mediates tyrosine phosphorylation of vascular endothelial cadherin induced by invasive breast cancer cells. J Biol Chem 287: 32981-32992, 2012.

10 Rezaei M, Friedrich K, Wielockx B, Kuzmanov A, Kettelhake A, Labelle M, Schnittler H, Baretton G and Breier G: Interplay between neural-cadherin and vascular endothelial-cadherin in breast cancer progression. Breast Cancer Res 14: R154, 2012.

11 Labelle M, Schnittler HJ, Aust DE, Friedrich K, Baretton G, Vestweber D and Breier G: Vascular endothelial cadherin promotes breast cancer progression via transforming growth factor beta signaling. Cancer Res 68: 1388-1397, 2008.

12 Higuchi K, Inokuchi M, Takagi Y, Ishikawa T, Otsuki S, Uetake $\mathrm{H}$, Kojima K and Kawano T: Cadherin 5 expression correlates with poor survival in human gastric cancer. J Clin Pathol 70: 217-221, 2017. 
13 D'Angelica M, Gonen M, Brennan MF, Turnbull AD, Bains M and Karpeh MS: Patterns of initial recurrence in completely resected gastric adenocarcinoma. Ann Surg 240: 808-816, 2004.

14 Lee IS, Yook JH, Kim TH, Kim HS, Kim KC, Oh ST and Kim BS: Prognostic factors and recurrence pattern in node-negative advanced gastric cancer. Eur J Surg Oncol 39: 136-140, 2013

15 Stiekema J, Cats A, Kuijpers A, van Coevorden F, Boot H, Jansen EP, Verheij M, Balague Ponz O, Hauptmann M and van Sandick JW: Surgical treatment results of intestinal and diffuse type gastric cancer. Implications for a differentiated therapeutic approach? Eur J Surg Oncol 39: 686-693, 2013.

16 Zheng HC, Zheng YS, Xia P, Xu XY, Xing YN, Takahashi H, Guan YF and Takano Y: The pathobiological behaviors and prognosis associated with Japanese gastric adenocarcinomas of pure WHO histological subtypes. Histol Histopathol 25: 445-452, 2010.

17 Japanese Gastric Cancer Association: Japanese classification of gastric carcinoma: 3rd English edition. Gastric Cancer 14: 101112, 2011.

18 Ryu KH, Shim KN, Jung SA, Yoo K, Joo YH and Lee JH: Significance of preoperative tissue levels of vascular-endothelial cadherin, liver-intestine cadherin and vascular endothelial growth factor in gastric cancer. Korean J Gastroenterol 60: 229-241, 2012.

19 van der Schaft DW, Hillen F, Pauwels P, Kirschmann DA, Castermans K, Egbrink MG, Tran MG, Sciot R, Hauben E, Hogendoorn PC, Delattre O, Maxwell PH, Hendrix MJ and Griffioen AW: Tumor cell plasticity in Ewing sarcoma, an alternative circulatory system stimulated by hypoxia. Cancer Res 65: 11520-11528, 2005.

20 Hess AR, Seftor EA, Gruman LM, Kinch MS, Seftor RE and Hendrix MJ: VE-cadherin regulates EphA2 in aggressive melanoma cells through a novel signaling pathway: implications for vasculogenic mimicry. Cancer Biol Ther 5: 228-233, 2006.

21 Corada M, Zanetta L, Orsenigo F, Breviario F, Lampugnani MG, Bernasconi S, Liao F, Hicklin DJ, Bohlen P and Dejana E: A monoclonal antibody to vascular endothelial-cadherin inhibits tumor angiogenesis without side effects on endothelial permeability. Blood 100: 905-911, 2002.

22 Liao F, Li Y, O’Connor W, Zanetta L, Bassi R, Santiago A, Overholser J, Hooper A, Mignatti P, Dejana E, Hicklin DJ and Bohlen P: Monoclonal antibody to vascular endothelial-cadherin is a potent inhibitor of angiogenesis, tumor growth, and metastasis. Cancer Res 60: 6805-6810, 2000.
23 Loges S, Clausen H, Reichelt U, Bubenheim M, Erbersdobler A, Schurr P, Yekebas E, Schuch G, Izbicki J, Pantel K, Bokemeyer $\mathrm{C}$ and Fiedler W: Determination of microvessel density by quantitative real-time PCR in esophageal cancer: correlation with histologic methods, angiogenic growth factor expression, and lymph node metastasis. Clin Cancer Res 13: 76-80, 2007.

24 Eom BW, Yoon H, Ryu KW, Lee JH, Cho SJ, Lee JY, Kim CG, Choi IJ, Lee JS, Kook MC, Park SR, Nam BH and Kim YW: Predictors of timing and patterns of recurrence after curative resection for gastric cancer. Dig Surg 27: 481-486, 2010.

25 Otsuji E, Kuriu Y, Ichikawa D, Ochiai T, Okamoto K, Hagiwara $\mathrm{A}$ and Yamagishi $\mathrm{H}$ : Clinicopathologic and prognostic characterization of poorly differentiated medullary-type gastric adenocarcinoma: World J Surg 28: 862-865, 2004.

26 Li M, Gu Y, Zhang Z, Zhang S, Zhang D, Saleem AF, Zhao X and Sun B: Vasculogenic mimicry: a new prognostic sign of gastric adenocarcinoma. Pathol Oncol Res 16: 259-266, 2010.

27 Nakanishi Y, Ohara M, Domen H, Shichinohe T, Hirano S and Ishizaka M: Differences in risk factors between patterns of recurrence in patients after curative resection for advanced gastric carcinoma. World J Surg Oncol 11: 98, 2013.

28 He R, Yang Q, Dong X, Wang Y, Zhang W, Shen L and Zhang $\mathrm{Z}$ : Clinicopathologic and prognostic characteristics of alphafetoprotein-producing gastric cancer. Oncotarget 8: 2381723830, 2017.

29 Rochefort P, Chabaud S, Pierga JY, Tredan O, Brain E, Bidard FC, Schiffler C, Polena H, Khalil-Mgharbel A, Vilgrain I and Bachelot T: Soluble VE-cadherin in metastatic breast cancer: an independent prognostic factor for both progression-free survival and overall survival. Br J Cancer 116: 356-361, 2017.
Received September 26, 2017

Revised October 10, 2017

Accepted October 11, 2017 